\title{
1 Four new Scopalina from Southern California: the first Scopalinida 2 (Porifera: Demospongiae) from the Eastern Pacific
}

\author{
THOMAS L. TURNER \\ Ecology, Evolution, and Marine Biology Department \\ University of California, Santa Barbara \\ Santa Barbara, CA 93106 \\ tlturner@ucsb.edu
}

ORCiD: 0000-0002-1380-1099

\begin{abstract}
Sponges (phylum Porifera) are common inhabitants of kelp forest ecosystems in California, but their diversity and ecological importance are poorly characterized in this biome. Here I use freshly collected samples to describe the diversity of the order Scopalinida in California. Though previously unknown in the Eastern Pacific Ocean, four new species are described here: Scopalina nnnn ${ }^{1}$ sp. nov., S. kkkk sp. nov., S. gggg sp. nov., and S. jjjj sp. nov.. These discoveries illustrate the considerable uncharacterized sponge diversity remaining in California kelp forests, and the utility of SCUBA-based collection to improve our understanding of this diversity.

\section{${ }^{1}$ Note regarding zoological nomenclature:}

Although this pre-print contains phrases such as "new species," it is not issued as part of the public and permanent scientific record for the purposes of zoological nomenclature. A similar form of this work will soon be published in a peer-reviewed scientific journal and will validate the nomenclatural acts herein. Placeholder dummy names such as "S. nnn" will be replaced upon publication of the peer-reviewed version.
\end{abstract}




\section{Introduction}

The order Scopalina is young: it was created in 2015 (Morrow \& Cárdenas 2015). The independent evolution of this lineage, however, is old. Phylogenies based on ribosomal DNA place the order, together with the freshwater sponges, as the sister clade to all other extant orders in the subclass Heteroscleromopha (Morrow et al. 2013). This interesting phylogenetic position motivates further investigation of this poorly known group. The order is comprised of only two genera, Scopalina and Svenzea, though genetic data suggest Stylissa flabelliformis may also be in the order (other genotyped Stylissa cluster with the order Agelisida (Erpenbeck et al. 2006; Morrow et al. 2012; Morrow \& Cárdenas 2015)). Little has been published on the biology of these genera, though advances have been made on the population genetics and symbiont relationships in several species (Blanquer \& Uriz 2008, 2011; Lee et al. 2009; Souza et al. 2017). Some Scopalinida have also been found to be sources for novel anti-microbial or anti-tumor compounds, which further motivates efforts to characterize their diversity (Avilés et al. 2013; Vicente et al. 2015; Wei et al. 2007).

Nearly all Scopalinida are described from warm waters in the Mediterranean, Caribbean, South-West Pacific, and Madagascar (van Soest et al. 2019b). The only previous exception to this pattern are the two most recently described species, from the Falkland Islands, which were found by hand-collecting sponges while SCUBA diving (Goodwin et al. 2011). Collecting by hand has been shown to be a productive way to discover new sponges from rocky areas in the shallow subtidal (Goodwin et al. 2011; Goodwin \& Picton 2009), but past sponge surveys in Southern California have primarily been conducted via dredging or by collecting in the intertidal zone (Bakus \& Green 1987; Green \& Bakus 1994; de Laubenfels 1932; Sim \& Bakus 1986). As a result, some common sponges found in California kelp forests - which occur on shallow hardbottom substrate - are unknown to science. Kelp forests in California are experiencing rapid changes due to anthropogenic impacts, and considerable work is focused on understanding kelp forest ecology to better predict and/or mitigate these impacts (Caselle et al. 2018; Castorini et al. 2018; Eger et al. 2020; Miller et al. 2018; Reed et al. 2016). The roles that sponges play in this ecosystem are unknown, but describing the species composition of the system represents a first and necessary step to improving this understanding. To better understand the abundance and distribution of shallow-water marine sponges in California, I have used SCUBA to collect over 300 individuals, mostly from kelp forest habitats in the Santa Barbara Channel. I have previously used this collection to revise the order Tethyida in California (Turner 2020b), but the other sponges remain to be described. Though the Scopalinida were not previously known from the Eastern Pacific, nine of these new samples can be assigned to this order. These samples are described herein as four new species in the genus Scopalina.

\section{Methods}

\section{Collections}

I collected sponge samples by hand with a knife. Each sample was placed immediately in a ziplock bag with copious seawater. After the dive, these bags were put on ice for 2-12 hours. Samples were then preserved in 95\% ethanol, which was exchanged for new preservative after 13 days, and changed again if it remained cloudy. Samples were vouchered with the California Academy of Sciences in San Francisco; collection numbers are listed in table S1. 
Samples were photographed underwater with an Olympus TG5 before collection. I sites could be used to form hypotheses about sponge distributions and habitat. Table $\mathrm{S} 2$ contains information about all locations investigated, together with an estimate of search effort at each location. Most (50/57) locations were subtidal sites that were searched while diving. These were generally shallow $(<15 \mathrm{~m}$ ) rocky reefs, but a few sites were deeper (up to $27 \mathrm{~m}$ ) and include artificial reefs and oil rigs. I also searched three intertidal areas and floating docks at four harbors. Scopalinida were only found at the shallow, kelp forested, natural reefs. Field photos of all sponges have been archived with vouchers, and also posted as searchable, georeferenced records on the site iNaturalist.org (table S1).

Spicules

Spicule preps were performed by digesting soft tissue subsamples in bleach. With the spicules settled at the bottom of the reaction tube, the bleach was then pipetted off and replaced with distilled water; this was repeated several times. Spicules were imaged using a D3500 SLR camera (Nikon) with a NDPL-1 microscope adaptor (Amscope) attached to a compound triocular microscope. A calibration slide was used to determine the number of pixels per $\mathrm{mm}$, and spicules were then measured using ImageJ (Schneider et al. 2012). Spicule length was measured as the longest possible straight line from tip to tip, even when spicules were curved or bent. Spicule width was measured at the widest point (near the head). All spicule measurements are included as supplementary data. To image spicular architecture, I hand-cut perpendicular sections and, when possible, removed sections of ectosome. Sections were digested in a mixture of $97 \%$ Nuclei Lysis Solution (Promega; from the Wizard DNA isolation kit) and 3\% 20mg/ml Proteinase K (Promega). This digestion eliminates cellular material while leaving the spongin network intact.

\section{Genotyping}

I extracted DNA from some samples with the Qiagen Blood \& Tissue kit, and used the Qiagen Powersoil kit on others; downstream results did not differ based on the kit used. At the cox 1 locus, a 1200 bp fragment was amplified with the following primers (LCO1490: 5'-GGT CAA CAA ATC ATA AAG AYA TYG G-3'; COX1-R1: 5'-TGT TGR GGG AAA AAR GTT AAA TT-3'); these amplify the "Folmer" barcoding region and the "col-ext" region used by some sponge barcoding projects (Rot et al. 2006). These primers failed to yield a product in $S$. jjjj sp. nov. I attempted to use the Folmer primers LCO1490 and HCO2198 in this species (Folmer et al. 1994), but these failed to amplify a unique product, likely due to the large number of symbionts present.

Two primer sets were used to amplify a portion of the $28 \mathrm{~S}$ rDNA nuclear locus. Most samples were sequenced over the $\sim 800 \mathrm{bp}$ D1-D2 region using primers Por28S-15F (5'-GCG AGA TCA CCY GCT GAA T-3') and Por28S-878R (5'-CAC TCC TTG GTC CGT GTT TC-3') (Morrow et al. 2012). A few samples were sequenced using primers C2 (5'-GAA AAG AAC TTT GRA RAG AGA GT-3') and D2 (5'-TCC GTG TTT CAA GAC GGG-3') (Chombard et al. 1998). The C2-D2 region is a $\sim 50 \%$ subset of the D1-D2 region, including the most rapidly evolving region recommended by the sponge barcoding project. Both primer sets worked equally well in these samples. 
PCR was performed using a Biorad thermocycler (T100); the following conditions were use for the cox 1 locus: $95^{\circ} \mathrm{C}$ for $3 \mathrm{~min}$, followed by 35 cycles of $94^{\circ} \mathrm{C}$ for $30 \mathrm{sec}, 52^{\circ} \mathrm{C}$ for 30 sec, $72^{\circ} \mathrm{C}$ for 90 seconds, followed by $72^{\circ} \mathrm{C}$ for 5 minutes. The $28 \mathrm{~S}$ C2-D2 region was amplified with the same conditions, except a $57^{\circ} \mathrm{C}$ annealing temperature and 60 second extension time; the $28 \mathrm{~S}$ D1-D2 region used a $53^{\circ} \mathrm{C}$ annealing temperature and 60 second extension time. PCR was performed in $50 \mu \mathrm{l}$ reactions using the following recipe: $24 \mu \mathrm{l}$ nuclease-free water, $10 \mu \mathrm{l} 5 \mathrm{x}$ PCR buffer (Gotaq flexi, Promega), $8 \mu \mathrm{MgCl}, 1 \mu \mathrm{l}$ 10mM dNTPs (Promega), $2.5 \mu \mathrm{l}$ of each primer at $10 \mu \mathrm{M}, 0.75$ bovine serum albumin $(10 \mathrm{mg} / \mathrm{ml}$, final conc $0.15 \mathrm{mg} / \mathrm{ml}), 0.25 \mu \mathrm{Taq}$ (Gotaq flexi, Promega), $1 \mu$ template. ExoSAP-IT (Applied Biosystems) was used to clean PCRs, which were then sequenced by Functional Biosciences using Big Dye V3.1 on ABI 3730xl instruments. PCR products were sequenced in both directions, and a consensus sequence was constructed using Codon Code v.9 (CodonCode Corporation). Blastn was used to verify that the resulting traces were of sponge origin. All sequences have been deposited in Genbank; accession numbers are listed in table S1.

\section{Genetic analysis}

I used the NCBI taxonomy browser to compile data from all samples identified as belonging to the order Scopalinida. I also used blastn to search for additional sequences that appeared to fall within this order, but found none. At the $28 \mathrm{~S}$ locus, data from Genbank was only included in the phylogeny if the highly variable C2-D2 region was included. Sequences at cox1 were included if they contained the Folmer barcoding region. Supplementary table S2 lists every Genbank accession found and explains the reasons why any were excluded. Together, included data are from 18 different publications (Blanquer \& Uriz 2008; Erpenbeck et al. 2002, 2006, 2007a; b, 2012, 2016; Kandler et al. 2019; Lavrov et al. 2005; Lavrov \& Lang 2005; Montalvo \& Hill 2011; Morrow et al. 2012, 2013; Nichols 2005; Pett \& Lavrov 2015; Riesgo et al. 2013; Rot et al. 2006; Thacker et al. 2013). Sequence alignments were produced in Codon Code v.9 (CodonCode Corporation). Phylogenies were estimated with maximum likelihood using IQ-Tree (Nguyen et al. 2015; Trifinopoulos et al. 2016). Phylogenies are unrooted, and root placement in figures is based on a published phylogeny that had many more characters and representatives from more sponge orders, but limited taxon sampling within the Scopalinida (Morrow et al. 2013). I used the Ultrafast bootstrap (Hoang et al. 2018) to measure node confidence. Phylogenies were produced from the IQ-Tree files using the Interactive Tree of Life webserver (Letunic \& Bork 2019). Figures were made ready for publication using R (r-project.org) and/or Gimp (gimp.org).

\section{Results}

\section{Genetic Results}

Figure 1 shows the phylogentic tree of newly collected samples, previously sequenced Scopalinida, and outgroups at the $28 \mathrm{~S}$ nuclear locus (the large ribosomal subunit). The four new species from California form a clade with three previously sequenced Scopalina, with Svenzea zeai as the closest outgroup. No other closely related sequences could be found in Genbank, so these data support inclusion of the new species in the genus Scopalina. I was also able to sequence the mitochondrial locus cox1 (also known as CO1) from three of the new species. New species once again formed a clade with other Scopalinida (figure 2). Svenzea zeai made 
Scopalina polyphyletic at this locus, but this placement did not have strong bootstrap support $(59 \%)$.

Both gene trees place two of the new species, $S$. kkkk and $S$. gggg, as the closest relatives to each other. This raises the question of whether these two species may in fact be a single species. However, these vouchers are different at $4.4 \%$ of sites at the cox 1 locus, and $4.5 \%$ of sites at the $28 \mathrm{~S}$ locus. The magnitude of this difference is similar to species-level divergence among other Porifera. A review of genetic distances at cox 1 found an average $4.9 \%$ sequence divergence between any individual sponge sequence and the most closely related sequence available from another species ( $\mathrm{N}=57$, (Huang et al. 2008)). A more recent analysis of 39 species in the poriferan order Suberitida found 3.7\% divergence at this same locus (Turner 2020a). Together with the morphological differences detailed below, these data support species status for both $S$. kkkk and S. gggg.

Figure 1. Gene tree at the large ribosomal subunit (28S). Bootstrap values are shown for nodes with $>80 \%$ support; nodes with $<50 \%$ support are collapsed. Genbank accession numbers are shown; those beginning with MT, in bold, are new. Scale bar indicates substitutions per site. Root placement based on Redmond et al. (2013).

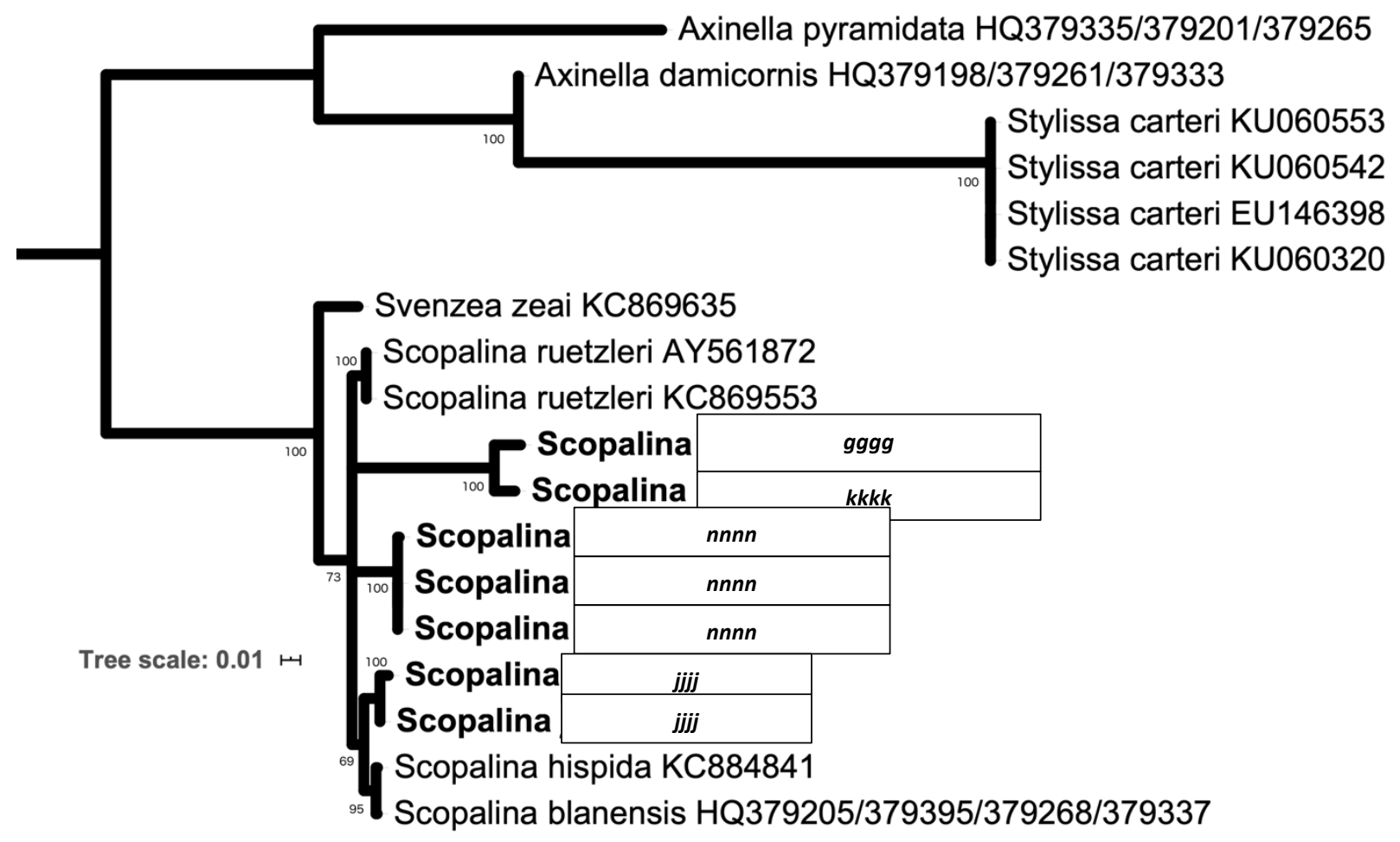


Figure 2. Gene tree at the cox 1 mitochondrial locus. Bootstrap values are shown for nodes with $>80 \%$ support; nodes with $<50 \%$ support are collapsed. Genbank accession numbers are shown; those beginning with MT, shown in bold, are new. Scale bar indicates substitutions per site. Root placement based on Redmond et al. (2013).

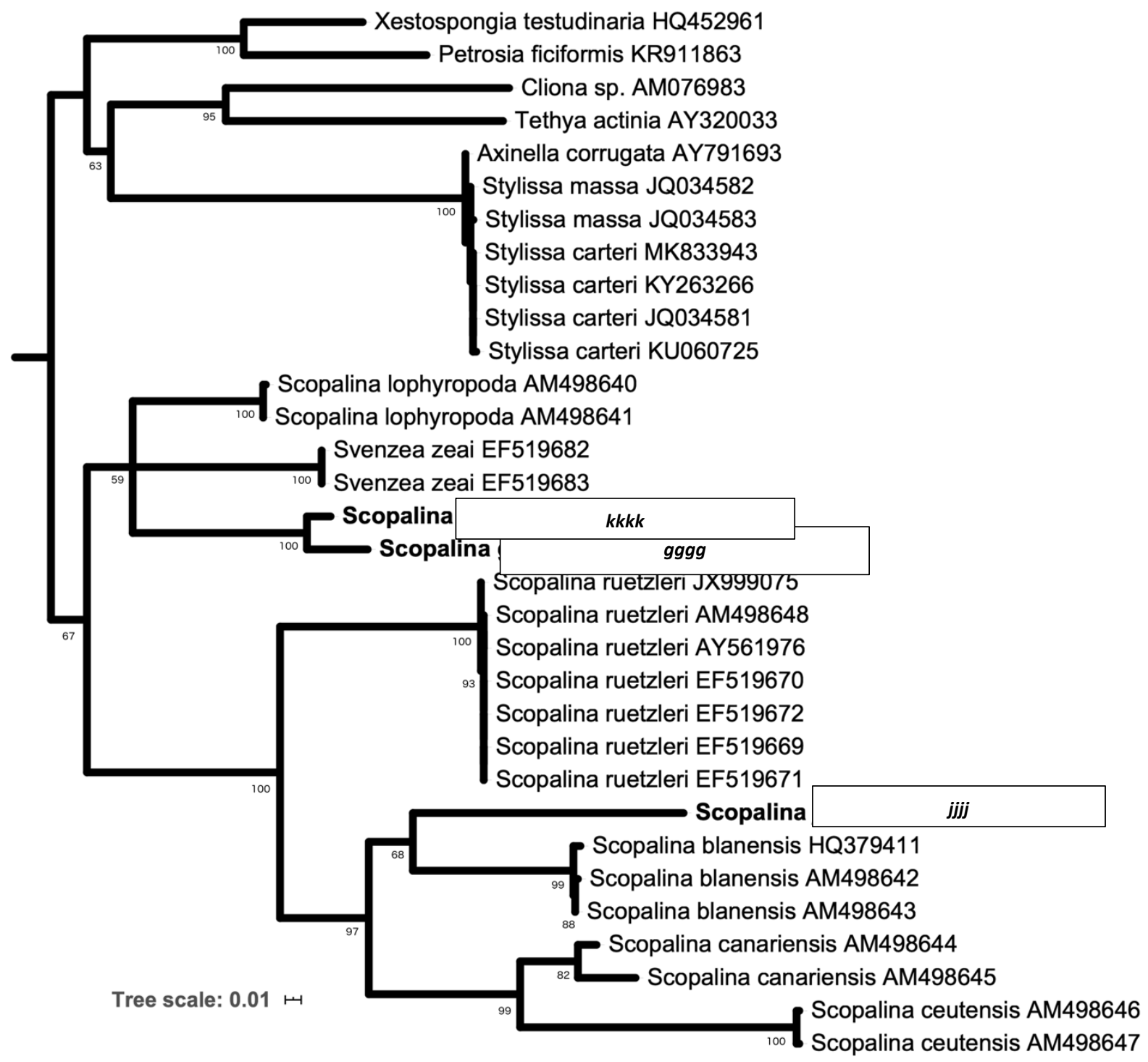


Systematics

Definition: Encrusting, massive or erect flabellate growth forms; smooth or conulose surface supported by prominent spongin fibres cored with spicules; megascleres styles and/or oxeas, often with telescoped ends; no ectosomal skeleton; tissue contains an unusual cell type filled with refractile granules. (Modified from Morrow and Cárdenas (Morrow \& Cárdenas 2015) to include oxeas among megascleres.)

Remarks: As the focus of this paper is alpha taxonomy, rather than a revision of higher taxonomy, I have retained the definition of Morrow and Cardenas (Morrow \& Cárdenas 2015), adding oxeas among the megascleres as the only modification. However, it should be noted that a more thorough revision is needed, and would likely result in further changes. The description of Svenzea zeai, for example, does not include prominent spongin fibers.

\section{F. Scopalinidae Morrow et al. 2012}

Definition same as order.

\section{Scopalina Schmidt 1862}

Definition: Thinly or thickly encrusting; soft and compressible; few or no ectosomal spicules; spongin abundant, with extensions of spongin manifest as mounds or fibers arising from basal spongin plate; these fibers may branch and merge; choanosomal skeleton of spicules or spicule bundles with proximal ends or entire spicule enclosed in spongin; choanosome may have a grainy appearance. Larvae are elongated, conical; anterior region wider than the posterior zone; completely covered by short cilia. (Modified from Blanquer and Uriz 2008 (Blanquer \& Uriz 2008)).

Diagnosis: Scopalina have abundant spongin, while Svenzea are described as having limited spongin, primarily at the nodes of a reticulated spicule network. Svenzea tend to have shorter spicules, (200-300 um), whereas in Scopalina they mostly range from 400 to 2000 (though $S$. canariensis averages only $199 \mathrm{um}$ ). The skeletal architecture of Svenzea has been noted as more like that of the haplosclerida than Scopalina. Svenzea are massive or thickly encrusting, while Scopalina are thinly to thickly encrusting.

Stylissa are erect, flabellate, or lobate, rather than possessing encrusting morphologies seen in Scopalina. Stylissa are noted as having a skeletal architecture like that of the 
242

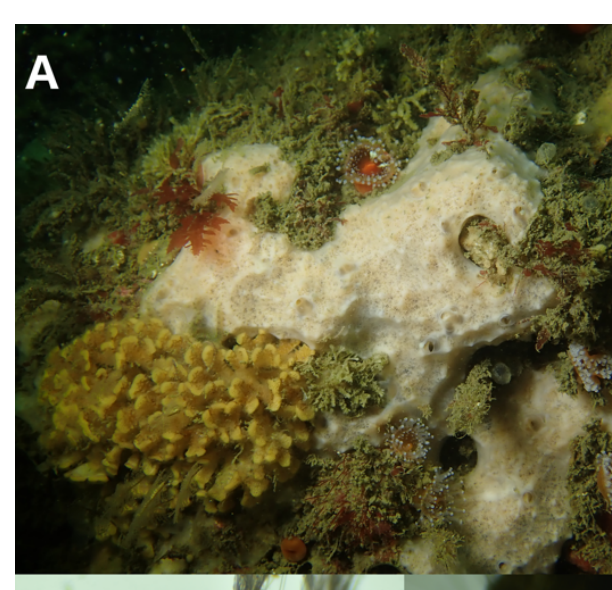

C
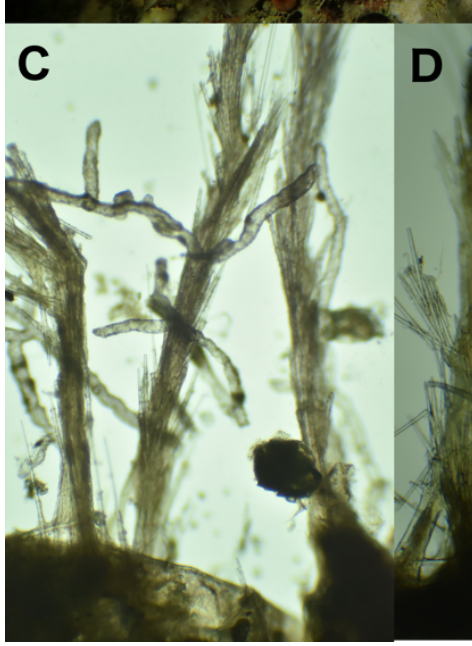
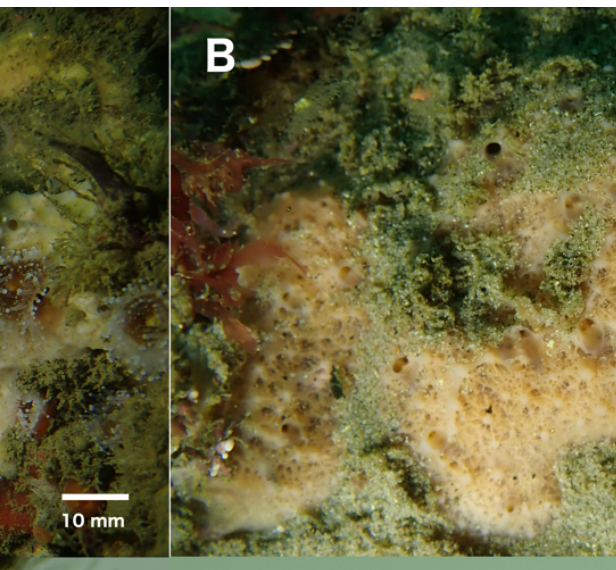

E

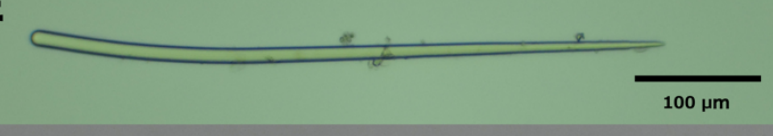

$\mathbf{F}$

Figure 3. Scopalina nnnn. A: Field photo of paratype (CASIZ TBD), Isla Vista Reef. B: Field photo of paratype (CASIZ TBD), Arroyo Quemado Reef. C, D: Skeletal architecture of holotype (CASIZ TBD), Point Loma; scale applied to both. In C, vermiform and primary spongin trunks are coated in apparent algae. In $\mathrm{D}$, only primary spongin trunk showing algae, but vermiform tracts are sporadically cored with sediment. E, F: spicules from paratype (CASIZ TBD).

Material examined. Holotype: (CASIZ TBD) Point Loma, San Diego, California, USA (32.69438, -117.26860), 15 m depth, 2/7/20. Paratypes: (CASIZ TBD) Coal Oil Point, Santa Barbara, California, USA (34.40450, -119.87890), $11 \mathrm{~m}$ depth, 8/30/19; (CASIZ TBD) Isla Vista Reef, Santa Barbara, California, USA (34.40278, -119.85755), $12 \mathrm{~m}$ depth, 8/1/19; (CASIZ TBD) Arroyo Quemado Reef, Santa Barbara, California, USA (34.46775, -120.11905), $11 \mathrm{~m}$ depth, $1 / 7 / 20$.

\section{Etymology. Suppressed for Bioarchive}

Morphology. Encrusting, 2 - $4 \mathrm{~mm}$ thick, up to $10 \mathrm{~cm}$ across (figure 3). Soft and compressible. Prominent conules $0.5-1.0 \mathrm{~mm}$ in height, 1.5 - $3.5 \mathrm{~mm}$ apart; spicules protrude at conules, making them microscopically hispid. Scattered oscules $1-2 \mathrm{~mm}$ in diameter. In nature, ectosome appears opaque at conules but often lacy and porous between them; ectosome more 
opaque in collected samples. Ectosome peach colored, choanosome yellow when alive; all tissues fade to beige when preserved in ethanol.

Skeleton. Vertical trunks of spongin, 100 - $550 \mu \mathrm{m}$ wide, arise from a basal spongin mat and terminate in surface conules. Secondary branches of spongin $50-100 \mu \mathrm{m}$ wide arise from primary trunks, branching off at an angle of less than 90 degrees and still extending towards surface. Primary and secondary trunks cored with spicules with pointed ends up; spicules entirely enclosed in spongin or with tips projecting; projecting tips fan out to create a bouquet that pierces the ectosome at conules. An additional type of spongin tract is distinct from those described above: 60 - $90 \mu \mathrm{m}$ wide, these tracts branch from primary trunks at approximately 90degree angles, then meander through the choanosome in a vermiform fashion, sometimes branching; these vermiform tracts do not contain spicules. Basal spongin, spicule-containing spongin trunks, and vermiform tracts are sporadically cored with sediment. Spicule-containing and vermiform spongin tracts are often filled and/or coated with what appear to be algal cells; these are red in preserved tissue.

Spicules. Styles only, usually bent towards the head end, thickest at the head and tapered to a point. Some show "telescoping" (width decreasing in a step-wise fashion) at the pointed end. Average spicule length for each voucher: 454, 483, 505, $532 \mu \mathrm{m}(\mathrm{N}=31-40$ per sample); total range in spicule length across vouchers $375-623 \mu \mathrm{m}(\mathrm{N}=135)$. Average spicule width at head, for each voucher: $9,9,11,11 \mu \mathrm{m}(\mathrm{N}=31-40$ per sample); total range in spicule width at head 5-17 $\mu \mathrm{m}(\mathrm{N}=135)$.

Distribution and habitat. This species is common on the shallow (5-16 m) rocky reef at Coal Oil Point, Santa Barbara, California. Often found on vertical rock walls or boulders, it can also occur on flatter areas, and has been found partially buried by sand. It was not found at most other locations investigated, but was located in similar habitat at the Arroyo Quemado Reef (near Point Conception) and in the kelp forests in extreme Southern California, off Point Loma, San Diego. It is therefore likely that the specie's range encompasses at least the Southern Californian and Ensenadan biogeographical provinces, bounded by Point Conception in the North and Punta 293 Eugenia in the South (Blanchette et al. 2008; Valentine 1966).

Remarks. Skeletal architecture, spiculation, and 28S genotype all conspire to place this species within the Scopalina. I was unable to detect the "graininess" said to characterize other Scopalinidae. However, this was hard to assess due to the abundant sediment within the sponge: dark grains were apparent, but appeared to be sediment rather than refractile cells.

Spicule dimensions, skeletal morphology, and genotype all serve to differentiate $S$. naussicae sp. nov. from the three other species newly described here. Fourteen other species are currently placed in the genus Scopalina, according to the World Porifera Database (van Soest et al. 2019a). None of these are known from the Eastern Pacific, making them unlikely conspecifics with any of the species described here. The gross morphology of S. naussicae sp. nov. in the field is quite similar to published images of $S$. ruetzleri (Wiedenmayer 1977) (West Atlantic) and S. erubescens (Goodwin et al. 2011) (Faulkland Islands). Spicules length and color also match $S$. erubescens better than other Scopalina, making this species the most likely conspecific. In addition to geographic separation, however, S. erubescens is larger, more thickly encrusting, and 
has thicker spicules and spicule bundles. The description of $S$. erubescens also lacks any mention of the vermiform spongin tracts that pervade $S$. nnnn sp. nov. (Goodwin et al. 2011).

Within its range, it is likely that this sponge can be identified from field photos, as I have seen no other sponge with a similar morphology to date.
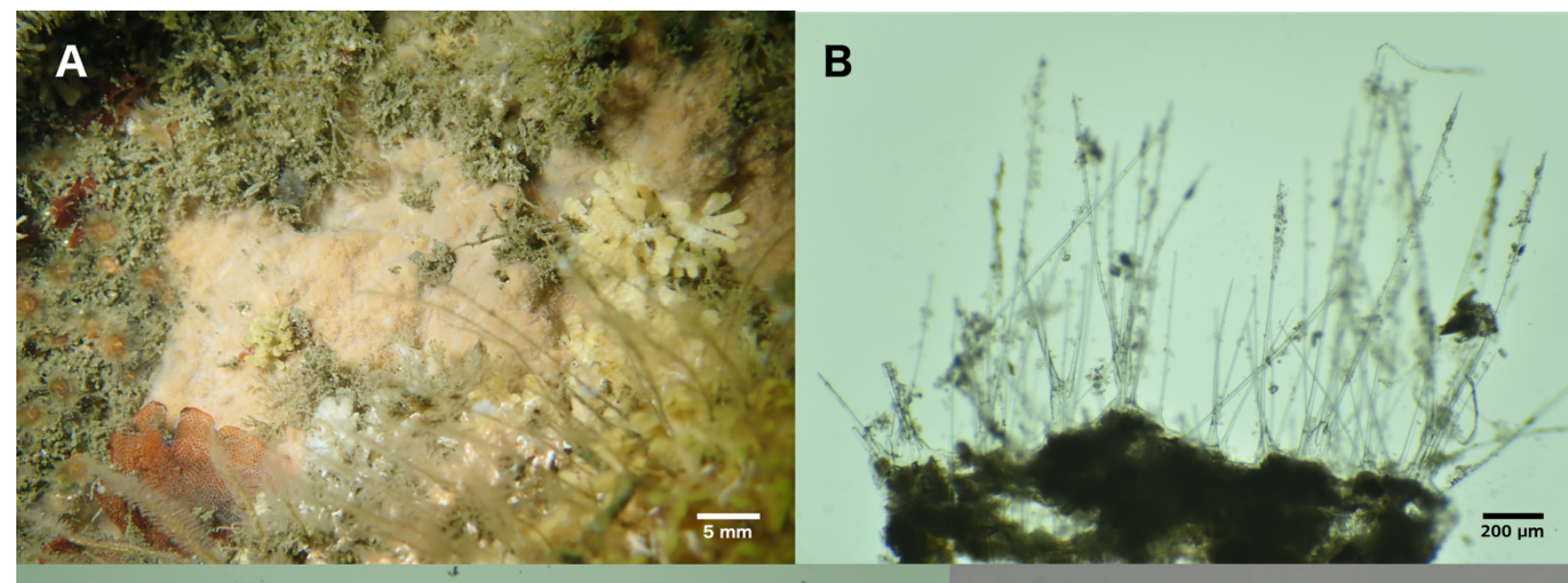

Figure 4. Scopalina kkkk. All images from holotype. A: field photo. B: Skeletal architecture, showing basal plate cored with copious sediment. C, D spicules.

Material examined. Holotype: (CASIZ TBD) Naples Reef, Santa Barbara, California, USA (34.42212, -119.95154), $12 \mathrm{~m}$ depth, 7/31/19.

\section{Etymology. Suppressed for Bioarchive}

Morphology. Encrusting, 1-2 mm thick, $6 \mathrm{~cm}$ across (figure 4). Soft and compressible. Surface hispid due to a profusion of protruding styles. Distinct ectosome not apparent. Peach colored in nature, except for translucent-white varicose channels running along surface/ Few scattered oscules, each $\sim 300 \mu \mathrm{m}$ diameter; smaller pores (approximately $80 \mu \mathrm{m}$ diameter) abundant and uniformly distributed. Beige when preserved in ethanol.

Skeleton. Basal mat of spongin cored with sediment. Extensions of spongin arise from this mat: most are low mounds, some only 25-50 $\mu \mathrm{m}$ high, but some are fingers 100-300 $\mu \mathrm{m}$ high and cored with sediment. Heads of spicules are embedded in these mounds and fingers, either singly or in bundles of up to 12 . Spicules extent vertically and pierce the surface of the sponge. 
Spicules. Styles only, usually bent towards the head end, thickest at the head and tapered to a point. Some spicule tips are "telescoping" (width decreasing in a step-wise fashion) at the pointed end. Spicules averaged $1557 \mu \mathrm{m}$ in length $(\mathrm{N}=35$, range 8769-1948 $\mu \mathrm{m}) ; 16 \mu \mathrm{m}$ in width $(\mathrm{N}=35$, range $11-21)$.

Distribution and habitat. Only a single individual has been found, on a vertical wall at $12 \mathrm{~m}$ depth, at Naples Reef, in Santa Barbara, California. Habitat was rocky reef with abundant bryozoan, sponge, and anthozoan cover, adjacent to year-round kelp forest. Three additional dives at the same location failed to locate other individuals; similar, nearby habitat to the East and West also had considerable search effort, so this species appears to be rare in this area.

Remarks. This sponge is quite genetically and morphologically distinct from $S$. nnnn and $S$. jjjj. The spicular architecture is fairly similar to $S$. gggg, though the spicule density is lower. As a rubbery strips that curl up upon themselves. Also, the spicules average over twice as long in $S$. $k k k k$, with non-overlapping size ranges among the spicules measured. Together with the considerable genetic divergence, these differences support species status for both species.

Among Scopalina from other regions, the only species with spicules as large as $S$. $k k k k$ are S. lophyropoda (Blanquer \& Uriz 2008; Schmidt 1862) (Mediterranean) and S. bunkeri (Goodwin et al. 2011) (Falkland Islands). In addition to great geographic distance, $S$. lophyropoda can be excluded based on genetic data (figure 2); S. bunkeri has a different spicular architecture, gross morphology, and color (Goodwin et al. 2011).

It does not seem likely that this species can be identified from field photos alone, though it is difficult to say if there are reliable field marks until more individuals are found. 


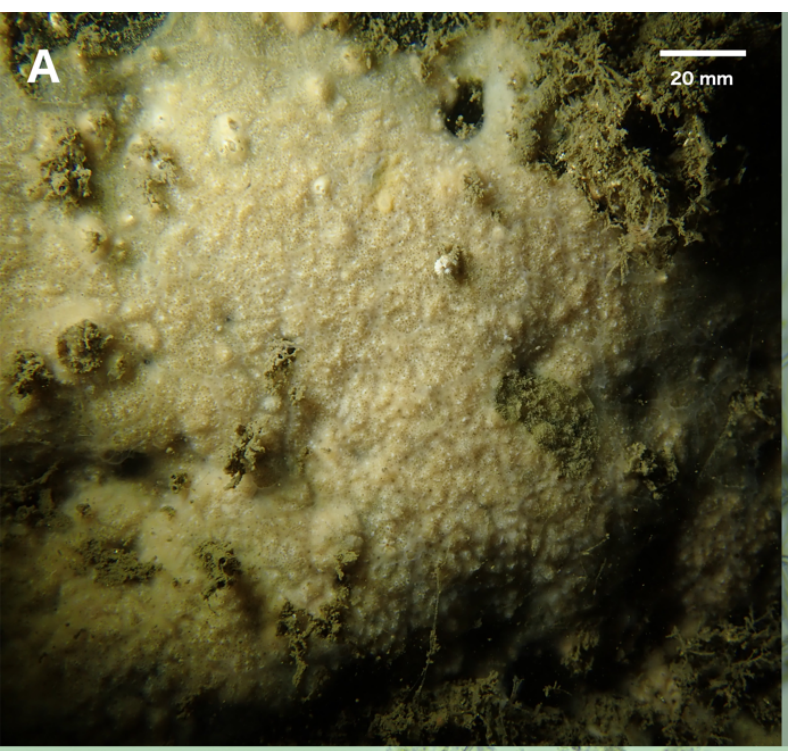

\section{B}

C
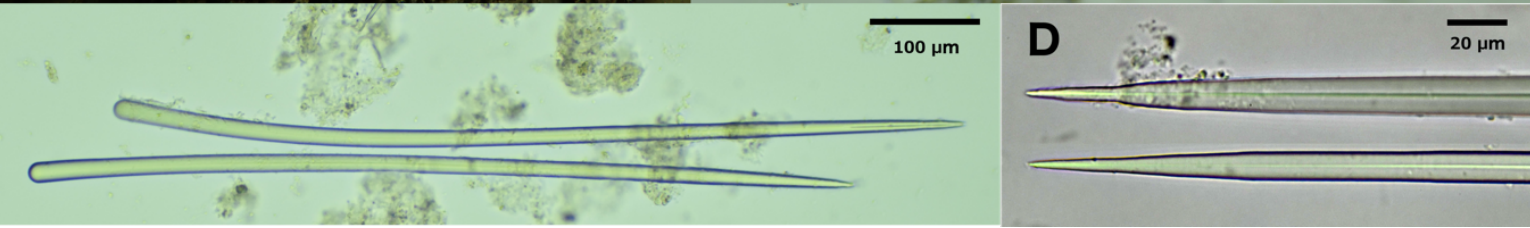

Figure 5. Scopalina gggg. All images from holotype. A: field photo. B: Skeletal architecture, showing basal plate cored with sediment. C, D spicules.

Material examined. Holotype: (CASIZ TBD) Elwood Reef, Santa Barbara, California, USA (34.41775, -119.90150), $12 \mathrm{~m}$ depth, 10/23/19.

\section{Etymology. Suppressed for Bioarchive}

Morphology. Encrusting, $1.0-1.2 \mathrm{~mm}$ thick, approximately $2.5 \mathrm{~cm}$ across (figure 5). Firm and incompressible. Surface hispid due to dense profusion of protruding styles. Distinct ectosome not apparent. Beige / cream colored in nature; retained the same color when preserved in ethanol. Surface traced by varicose, translucent channels; pores (approximately 200-300 $\mu \mathrm{m}$ diameter) abundant and uniformly distributed.

Skeleton. Basal mat of spongin cored with sediment. Vertical extensions of spongin 10-600 $\mu \mathrm{m}$ high arise from this mat: none of these were cored with sediment, but loose sediment was abundant throughout the sponge. Heads of some spicules are embedded singly, directly in the basal mat of spongin, but most are embedded as tiered bundles in the vertical extensions of spongin.

Spicules. Styles only, usually slightly bent towards the head end, thickest at the head and tapered to a point. Some spicule tips are "telescoping" (width decreasing in a step-wise fashion) at the 
389 pointed end. Spicules averaged $687 \mu \mathrm{m}$ in length $(\mathrm{N}=37$, range $388-801 \mu \mathrm{m}) ; 15 \mu \mathrm{m}$ in width $390 \quad(\mathrm{~N}=37$, range 6-21).

Distribution and habitat. Only a single individual has been found, on a vertical ledge at $12 \mathrm{~m}$ depth, at Elwood Reef, in Santa Barbara, California. Habitat was rocky reef with abundant bryozoan, sponge, and anthozoan cover, under a year-round kelp canopy. Considerable search effort at Elwood Reef and nearby locations failed to locate additional individuals, so this species is likely to be rare in this area.

Remarks. This species is most similar to $S$. $k k k k$, but is morphologically and genetically distinct, as detailed in the $S$. $k k k k$ remarks. The spicule dimensions are similar to several species from

400 other regions (S. azurea (Bibiloni 1993), S. blanensis (Blanquer \& Uriz 2008), S. hispida

401 (Hechtel 1965)), though none of these others is known to have spicules as thick. All but $S$.

402 azurea can also be excluded based on the available genetic data (figures 1,2). Conspecificity

403 with $S$. azurea is unlikely based on geographic isolation, color, and spicular architecture

404 (Bibiloni 1993).

It does not seem likely that this species can be identified from field photos alone, though 


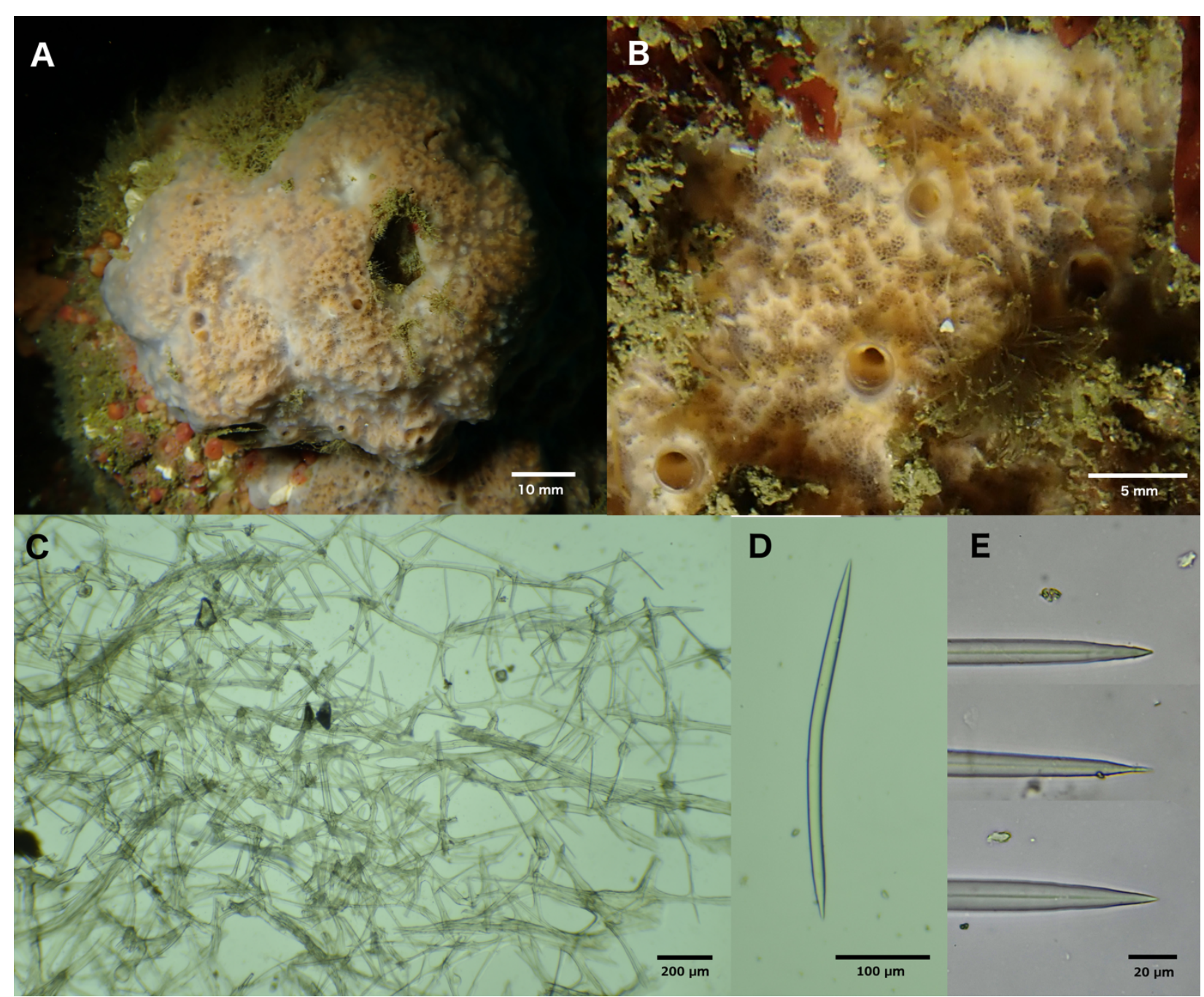

Figure 6. Scopalina jjjj. A: Field photo of holotype (CASIZ TBD), Santa Cruz Island. B: Field photo of paratype (CASIZ TBD), Naples Reef. C: Skeletal architecture of holotype. In C, vermiform and primary spongin trunks coated in apparent algae. D, E: spicules from paratype (CASIZ TBD).

Material examined. Holotype: (CASIZ TBD) Big Rock, Santa Cruz Island, California, USA (34.05220, -119.57360), 12m depth, 1/19/20. Paratypes: (CASIZ TBD) Naples Reef, Santa Barbara, California, USA (34.42212, -119.95154), $11 \mathrm{~m}$ depth, 9/26/19. (CASIZ TBD) Naples Reef, Santa Barbara, California, USA (34.42212, -119.95154), 15 m depth, 12/10/19.

\section{Etymology. Suppressed for Bioarchive}

Morphology. Thickly encrusting, $1.0-1.5 \mathrm{~cm}$ thick, up to $35 \mathrm{~cm}$ across (figure 6). Soft, spongey, and very compressible. Ectosome transparent, without spicules; a lattice-like mesh of spongin fibers visible in life; conules present, but very small (100-300 $\mu \mathrm{m}$ in width and height); 
ectosome more opaque after preservation in ethanol but remains partially transparent and lacy. Color in freshly collected specimens is terra-cotta (reddish-brown); red and orange tones are more muted in field photos, with color appearing to vary from tan to terra-cotta; samples fade to beige when preserved in ethanol. Oscules 10 - $20 \mathrm{~mm}$ in diameter; occur singly; sparse in some samples and denser in others; partially closed by ectosomal membrane in collected samples.

Skeleton. Abundant spongin fibers cored with spicules form a chaotic mesh lattice within choanosome. Larger spongin tracts, 45 - $65 \mu \mathrm{m}$ wide, are cored with bundles approximately 5 spicules wide; smaller tracts, 8 - $20 \mu \mathrm{m}$ wide, are cored with single spicules. No spicules detected outside of spongin tracts. Considerable silt apparent in tissue sections, but none seen coring spongin tracts.

Spicules. Oxeas only, gently curved; some spicule tips show "telescoping" (width decreasing in a step-wise fashion). Average spicule length for each voucher: $354,358,366 \mu \mathrm{m}(\mathrm{N}=30-37$ per sample); total range in spicule length across vouchers $219-436 \mu \mathrm{m}(\mathrm{N}=100)$. Average spicule width at widest point, for each voucher: $8,9,11 \mu \mathrm{m}(\mathrm{N}=30-37$ per sample); total range in spicule width at head 2-18 $\mu \mathrm{m}(\mathrm{N}=100)$.

Distribution and habitat. In the winter of 2019-2020, this sponge was abundant on the shallow (5-17 m) rocky reefs off of Naples Point and the Elwood Bluffs, Santa Barbara, California. The species was not seen in 4 dives at these same locations in the Spring and Summer of 2019, suggesting that the population may vary seasonally or in a boom-and-bust fashion on longer timescales. Consistent with this latter possibility, many large individuals of this species were seen at the Big Rock dive site at Santa Cruz Island in January of 2020, while no individuals were seen in three dives at the same location in November of 2018. The only other probable sighting I am aware of is a photo uploaded to the site iNaturalist (inaturalist.org/observations/41000570). This photo is very likely to be $S . j j j j$, as no other sponge with this morphology is known in Southern California. The photo is annotated as from Heisler Park, Laguna Beach, from 3/4/2007.

Remarks. Genetic data at two loci confirm that this species is within the Scopalina. Abundant spongin fibers cored with simple spicules, telescoping spicule tips, and lack of ectosomal skeleton are all consistent with this placement. The presence of oxeas, rather than styles, required modification of recent definitions of order, family, and genus -- though one species currently placed in Scopalina in the World Porifera database also contains only oxeas (S. agoga (de Laubenfels 1954)) and another contains both styles and oxeas (S. australiensis (Pulitzer-Finali 1982)). Scopalina jjjj is differentiated from $S$. agoga by spicule size and the presence of many tangential spicules in the ectosome of $S$. agoga; this previously described species is also known only from Palau (de Laubenfels 1954). The skeletal architecture of $S$. jjjj differs markedly from the other California species described herein due to its highly reticulated nature, but this is similar to the published description of the Atlantic species S. ceutensis (Blanquer \& Uriz 2008). It is likely that this sponge can be identified from field photos alone within Southern California, as I have seen no other sponge with a similar morphology to date.

\section{Conclusions}


It is remarkable that, among the relatively well-studied kelp forests of the Santa Barbara Channel, I was able to locate 4 new species from an order not known to occur in the Eastern Pacific. These species were not only undescribed, but apparently unsampled: no previous California survey includes samples matching their description (Lee et al. 2007). These results illustrate how much remains to be learned about the sponges of California, and show that SCUBA-based collection efforts can help bridge this gap. Moreover, collection by hand allows for underwater photography of live samples before collection. By comparing photographs of the species described here with photos of all other sponges I have collected, I believe that the two more common species ( $S$. jjjjj and $S$. nnnn) are easily recognizable within their range. This assertion is supported by the fact that, after collection of the first samples of each, subsequent samples were correctly identified as conspecifics based on field photos before being confirmed as such using spicules and DNA. This will simplify future efforts to understand the ecology of these species, perhaps by using diver surveys or photo transects.

In contrast, the other two new species ( $S . k k k k$ and $S . g g g g)$ are thinly encrusting and will be harder to identify based on gross morphology. Each was found only once; as they were both found within the range and habitat I have most thoroughly sampled, it is likely they are uncommon in this area (but could be common in deeper waters). Though describing new species from a single sample is not ideal, I feel confident these samples are not conspecific with any currently named species due to their considerable genetic divergence from other sequenced species, substantial morphological differences from un-genotyped species, and the fact that no previously named species are known from the Eastern Pacific.

Much remains to be learned about the Scopalinida. Twenty species were previously known to reside in the order: 14 Scopalina species, 5 Svenzea species, and Stylissa flabelliformis (Morrow \& Cárdenas 2015). These sponges are known from the Mediterranean and Canary Islands (5 species), Caribbean (6 species), the tropical South-West Pacific (6 species), Madagascar (1 species), and the Falkland Islands (2 species). The addition of four species from Southern California expands this range considerably, and makes the group more accessible to researchers in this geographic region. It is my hope that this will lead to an improved understanding of the ecology and evolution of these interesting and understudied animals.

\section{Acknowledgements}

I am grateful for the help and support of many people in UCSB's Marine Science Institute and Diving \& Boating Program, especially Robert Miller, Clint Nelson, Christoph Pierre, Frankie Puetzer, Christian Orsini, and H. Mark Page. Steve Lonhart (NOAA) and Shannon Myers (UCSC) were instrumental in facilitating collections in Central California, and the Natural History Museum of Los Angeles' DISCO program facilitated collections in Los Angeles County.

\section{Funding declaration}

Financial support was provided by UCSB and by the National Aeronautics and Space Administration Biodiversity and Ecological Forecasting Program (Grant NNX14AR62A); the Bureau of Ocean Energy Management Environmental Studies Program (BOEM Agreement 
520 Foundation in support of the Santa Barbara Coastal Long Term Ecological Research program

521 under Awards OCE-9982105, OCE-0620276, OCE-1232779, OCE-1831937. The funders had no

522 role in study design, data collection and analysis, decision to publish, or preparation of the

523 manuscript.

524

525

526

527

528

529

530

\section{References}

Avilés, E., Rodríguez, A.D. \& Vicente, J. (2013) Two rare-class tricyclic diterpenes with antitubercular activity from the Caribbean sponge Svenzea flava. Application of vibrational circular dichroism spectroscopy for determining absolute configuration. Journal of Organic Chemistry 78, 11294-11301.

Bakus, G.J. \& Green, K.D. (1987) The distribution of marine sponges collected from the 19761978 Bureau of Land Management Southern California Bight program. Bulletin of the Southern California Academy of Sciences 86, 57-88.

Bibiloni, M.A. (1993) Some new or poorly known sponges of the Balearic Islands (western Mediterranean). Scientia Marina 57, 307-318.

Blanchette, C., Miner, C., Raimondi, P., Lohse, D., Heady, K. \& Broitman, B. (2008) Biogeographical patterns of rocky intertidal communities along the Pacific coast of North America. Journal of Biogeography 35, 1593-1607.

Blanquer, A. \& Uriz, M.-J. (2008) "A posteriori” searching for phenotypic characters to described

Blanquer, A. \& Uriz, M.-J. (2011) "'Living together apart'”: The hidden genetic diversity of new cryptic species of sponges revealed by molecular markers (Scopalina:

Caselle, J.E., Davis, K. \& Marks, L.M. (2018) Marine management affects the invasion success of sponge populations. Molecular Biology and Evolution 28, 2435-2438.

Castorini, M.C.N., Reed, D.C. \& Miller, R.J. (2018) Loss of foundation species: disturbance frequency outweighs severity in structuring kelp forest communities. Ecology 99, 24422454.

Chombard, C., Boury-Esnault, N. \& Tillier, S. (1998) Reassessment of homology of morphological characters in tetractinellid sponges based on molecular data. Systematic Biology 47, 351-366. Silliman, B.R. \& Vergés, A. (2020) Playing to the positives: Using synergies to enhance 
Erpenbeck, D., Breeuwer, J., van der Velde, H. \& van Soest, R. (2002) Unravelling host and symbiont phylogenies of halichondrid sponges (Demospongiae, Porifera) using a mitochondrial marker. Marine Biology 141, 377-386.

Erpenbeck, D., Breeuwer, J.A.J., Parra-Velandia, F.J. \& van Soest, R.W.M. (2006) Speculation with spiculation?-Three independent gene fragments and biochemical characters versus morphology in demosponge higher classification. Molecular Phylogenetics and Evolution 38, 293-305.

Erpenbeck, D., Duran, S., Rützler, K., Paul, V., Hooper, J. \& Wörheide, G. (2007a) Towards a DNA taxonomy of Caribbean demosponges: a gene tree reconstructed from partial mitochondrial CO1 gene sequences supports previous rDNA phylogenies and provides a new perspective on the systematics of Demospongiae. Journal of the Marine Biological Association of the United Kingdom 87, 1563-1570.

Erpenbeck, D., Hall, K., Alvarez, B., Büttner, G., Sacher, K., Schätzle, S., Schuster, A., Vargas, S., Hooper, J. \& Wörheide, G. (2012) The phylogeny of halichondrid demosponges: past and present re-visited with DNA-barcoding data. Organisms Diversity \& Evolution 12, 57-70.

Erpenbeck, D., List-Armitage, S., Alvarez, B., Degnan, B., Wörheide, G. \& Hooper, J. (2007b) The systematics of Raspailiidae (Demospongiae: Poecilosclerida: Microcionina) re-analysed with a ribosomal marker. Journal of the Marine Biological Association of the United Kingdom 87, 1571-1576.

Erpenbeck, D., Voigt, O., Al-Aidaroos, A., Berumen, M., Büttner, G., Catania, D., Guirguis, A., Paulay, G., Schätzle, S. \& Wörheide, G. (2016) Molecular biodiversity of Red Sea demosponges. Marine Pollution Bulletin 105, 507-514.

Folmer, O., Black, M., Wr, H. \& Vrijenhoek, R. (1994) DNA primers for amplification of mitochondrial Cytochrome $\mathrm{C}$ oxidase subunit I from diverse metazoan invertebrates. Molecular marine biology and biotechnology 3, 294-299.

Goodwin, C., Jones, J., Neely, K. \& Brickle, P. (2011) Sponge biodiversity of the Jason Islands and Stanley, Falkland Islands with descriptions of twelve new species. Journal of the Marine Biological Association of the United Kingdom 91, 275-301.

Goodwin, C.E. \& Picton, B.E. (2009) Demosponges of the genus Hymedesmia (Poecilosclerida: Hymedesmidae) from Rathlin Island, Northern Ireland, with a description of six new species. Zoological Journal of the Linnean Society 156, 896-912.

Green, K.D. \& Bakus, G.J. (1994) Taxonomic atlas of the benthic marine fauna of the Western Santa Maria Basin and the Western Santa Barbara Channel. Volume 2: The Porifera. The Santa Barbara Museum of Natural History, $82 \mathrm{pp}$.

Hechtel, G.J. (1965) A systematic study of the Demospongiae of Port Royal, Jamaica. Bulletin of the Peabody Museum of Natural History 20, 1-103. 
Hoang, D., Chernomor, O., von Haeseler, A., Minh, B. \& Vinh, L. (2018) UFBoot2: Improving the ultrafast bootstrap approximation. Molecular Biology and Evolution 35, 518-522.

Huang, D., Meier, R., Todd, P.A. \& Chou, L.M. (2008) Slow mitochondrial COI sequence evolution at the base of the Metazoan tree and its implications for DNA barcoding. Journal of Molecular Evolution 66, 167-174.

Kandler, N., Wooster, M., Leray, M., Knowlton, N., de Voogd, N., Paulay, G. \& Berumen, M. (2019) Hyperdiverse macrofauna communities associated with a common sponge, Stylissa carteri, shift across ecological gradients in the Central Red Sea. Diversity 11, 18.

de Laubenfels, M.W. (1932) The marine and fresh-water sponges of California. Proceedings of the United States National Museum 81, 1-140.

de Laubenfels, M.W. (1954) The sponges of the West-Central Pacific. Oregon State College, Corvallis.

Lavrov, D., Forget, L., Kelly, M. \& Lang, B. (2005) Mitochondrial genomes of two demosponges provide insights into an early stage of animal evolution. Molecular Biology and Evolution 22, 1231-1239.

Lavrov, D. \& Lang, B. (2005) Transfer RNA gene recruitment in mitochondrial DNA. Trends in Genetics 21, P129-133.

Lee, O.O., Chui, P.Y., Wong, Y.H., Pawlik, J.R. \& Qian, P.-Y. (2009) Evidence for vertical transmission of bacterial symbionts from adult to embryo in the Caribbean sponge Svenzea zeai. Applied and Environmental Microbiology 75, 6147-6156.

Lee, W., Elvin, D. \& Reiswig, H. (2007) The sponges of California: A guide and key to the marine sponges of California. Monterey Bay Sanctuary Foundation, Monterey, CA.

Letunic, I. \& Bork, P. (2019) Interactive Tree Of Life (iTOL) v4: recent updates and new developments. Nucleic Acids Research 47, W256-W259.

Miller, R.J., Lafferty, K.D., Lamy, T., Kui, L., Rassweiler, A. \& Reed, D.C. (2018) Giant kelp, Macrocystis pyrifera, increases faunal diversity through physical engineering. Proceedings of the Royal Society B 285, 20172571.

Montalvo, N. \& Hill, R. (2011) Applied Environmental Microbiology 77, 7207-7216.

Morrow, C. \& Cárdenas, P. (2015) Proposal for a revised classification of the Demospongiae (Porifera). Frontiers in Zoology 12, 1-27.

Morrow, C.C., Picton, B.E., Erpenbeck, D., Boury-Esnault, N., Maggs, C.A. \& Allcock, A.L. (2012) Congruence between nuclear and mitochondrial genes in Demospongiae: A new 
hypothesis for relationships within the G4 clade (Porifera: Demospongiae). Molecular Phylogenetics and Evolution 62, 174-190.

Morrow, C.C., Redmond, N.E., Picton, B.E., Thacker, R.W., Collins, A.G., Maggs, C.A., Sigwart, J.D. \& Allcock, A.L. (2013) Molecular phylogenies support homoplasy of multiple morphological characters used in the taxonomy of Heteroscleromorpha (Porifera: Demospongiae). Integrative and Comparative Biology 53, 428-446.

Nguyen, L.-T., Schmidt, H., von Haeseler, A. \& Minh, B. (2015) IQ-TREE: A fast and effective stochastic algorithm for estimating maximum likelihood phylogenies. Molecular Biology and Evolution 32, 268-274.

Nichols, S. (2005) An evaluation of support for order-level monophyly and interrelationships within the class Demospongiae using partial data from the large subunit rDNA and cytochrome oxidase subunit I. Molecular Phylogenetics and Evolution 34, 81-96.

Pett, W. \& Lavrov, D. (2015) Cytonuclear interactions in the evolution of animal mitochondrial tRNA metabolism. Genome Biology and Evolution 7, 2089-2101.

Pulitzer-Finali, G. (1982) Some new or little-known sponges from the Great Barrier Reef of Australia. Bollettino dei Musei e degli Istituti Biologici dell'Universitá di Genova 48-49, 87-141.

Reed, D., Washburn, L., Rassweiler, A., Miller, R., Bell, T. \& Harrer, S. (2016) Extreme warming challenges sentinel status of kelp forests as indicators of climate change. Nature Communications 7, 13757.

Riesgo, A., Novo, M., Sharma, P., Peterson, M., Maldonado, M. \& Giribet, G. (2013) Inferring the ancestral sexuality and reproductive condition in sponges (Porifera). Zoologica Scripta 43, 101-117.

Rot, C., Goldfarb, I., Ilan, M. \& Huchon, D. (2006) Putative cross-kingdom horizontal gene transfer in sponge (Porifera) mitochondria. BMC Evolutionary Biology 6, 1-11.

Schmidt, O. (1862) Die Spongien des adriatischen Meeres. Wilhelm Engelmann, Leipzig, 88 pp.

Schneider, C., Rasband, W. \& Eliceiri, K. (2012) NIH Image to ImageJ: 25 years of image analysis. Natue Methods 9, 671-675.

Sim, C.J. \& Bakus, G.J. (1986) Marine sponges of Santa Catalina Island, California. Occasional Papers of the Allan Hancock Foundation 5, 1-23.

van Soest, R.W.M., Boury-Esnault, N., Hooper, J.N.A., Rützler, K., de Voogd, N.J., Alvarez, B., Hajdu, E., Pisera, A.B., Manconi, R., Schönberg, C., Klautau, M., Kelly, M., Vacelet, J., Dohrmann, M., Díaz, M.-C., Cárdenas, P., Carballo, J.L., Ríos, P., Downey, R. \& Morrow, C.C. (2019a) World Porifera Database. Scopalina. 
van Soest, R.W.M., Boury-Esnault, N., Hooper, J.N.A., Rützler, K., de Voogd, N.J., Alvarez, B., Hajdu, E., Pisera, A.B., Manconi, R., Schönberg, C., Klautau, M., Kelly, M., Vacelet, J., Dohrmann, M., Díaz, M.-C., Cárdenas, P., Carballo, J.L., Ríos, P., Downey, R. \& Morrow, C.C. (2019b) World Porifera Database. Scopalinida.

Souza, D.T., da Silva, F.S.P., da Silva, L.J., Crevelin, E.J., Moraes, L.A.B., Zucchi, T.D. \& Melo, I.S. (2017) Saccharopolyspora spongiae sp. nov., a novel actinomycete isolated from the marine sponge Scopalina ruetzleri (Wiedenmayer, 1977). International Journal of Systematic and Evolutionary Microbiology 67.

Thacker, R., Hill, A., Hill, M., Redmond, N., Collins, A., Morrow, C., Spicer, L., Carmack, C., Zappe, M., Pohlmann, D., Hall, C., Diaz, M. \& Bangalore, P. (2013) Nearly complete 28S rRNA gene sequences confirm new hypotheses of sponge evolution. Integrative and Comparative Biology 53, 373-387.

Trifinopoulos, J., Nguyen, L.-T., von Haeseler, A. \& Minh, B. (2016) W-IQ-TREE: a fast online phylogenetic tool for maximum likelihood analysis. Nucleic Acids Research 44, W232W235.

Turner, T.L. (2020a) The marine sponge Hymeniacidon perlevis is a globally-distributed invasive species. Bioarxve doi: 10.1101/2020.02.13.948000.

Turner, T.L. (2020b) The order Tethyida (Porifera) in California: taxonomy, systematics, and the first member of the family Hemiasterellidae in the Eastern Pacific. Bioarxve doi: 10.1101/2020.04.05.026518.

Valentine, J. (1966) Numerical analysis of marine molluscan ranges on extratropical northeastern Pacific shelf. Limnology and Oceanography 11, 198-211.

Vicente, J., Stewart, A.K., van Wagoner, R.M., Elliott, E., Bourdelais, A.J. \& Wright, J.L.C. (2015) Monacyclinones, new angucyclinone metabolites isolated from Streptomyces sp. M7_15 associated with the Puerto Rican sponge Scopalina ruetzleri. Marine Drugs 13, 46824700.

Wei, X., Rodríguez, A.D., Wang, Y. \& Franzblau, S.G. (2007) Novel ring B abeo-sterols as growth inhibitors of Mycobacterium tuberculosis isolated from a Caribbean Sea sponge, Svenzea zeai. Tetrahedron Letters 48, 8851-8854.

Wiedenmayer, F. (1977) Shallow-water sponges of the western Bahamas. Experientia Supplementum 28, 1-287. 